\title{
A fraction of methylene chloride from Geum japonicum Thunberg inhibits tumor metastatic and angiogenic potential
}

\author{
JIN-CHUL HEO ${ }^{1}$, MINSIK SON ${ }^{2}$, SANG-UK WOO ${ }^{2}$, MI-AE KWEON ${ }^{2}$, EUN KYUNG YOON ${ }^{2}$, \\ HEE KYUNG LEE ${ }^{3}$, WON-SIK CHOI ${ }^{3}$, KANG-JIN CHO ${ }^{4}$ and SANG-HAN LEE ${ }^{1,2,3}$
}

\author{
${ }^{1}$ Food and Bio-Industry Research Institute, Departments of ${ }^{2}$ Food Science and Biotechnology and ${ }^{3}$ Nano-Science and \\ Technology, Graduate School, Kyungpook National University, Daegu 702-701; ${ }^{4}$ Department of Molecular Physiology and \\ Biochemistry, National Institute of Agricultural Biotechnology (NIAB), Suwon 441-707, Korea
}

Received September 4, 2007; Accepted October 24, 2007

\begin{abstract}
The plant Geum japonicum Thunberg (GjT) has been used as a diuretic in traditional medicine. Herein, we report that the $\mathrm{G} j \mathrm{~T}$ extract blocks both the spread of human umbilical vein endothelial cells (HUVECs) on matrigel and the migration of B16 cells. We used various assays to test for cell attachment, spreading, wound healing and angiogenesis. A reverse transcription-polymerase chain reaction (RT-PCR) and a mitogen-activated protein kinase (MAPK) assay were also carried out for the mechanistic study of GjT. Our results showed that a fraction of methylene chloride fraction from $\mathrm{Gj} \mathrm{T}$ inhibited B16 cells during cell attachment and migration and suppressed tube formation in a dose-dependent manner. An RT-PCR analysis showed that the methylene chloride extract decreased the mRNA expression of CD44 and TIMP-2. A Western blot analysis of the phosphorylation of MAPK kinases (ERK, JNK and p38) showed that the GjT fraction increased the expression of phospho-JNK, suggesting that GjT has the potential to alleviate metastatic and angiogenic activity, via a phospho-JNK signaling pathway.
\end{abstract}

Correspondence to: Professor Sang-Han Lee, Department of Food Science and Biotechnology, Kyungpook National University, Daegu 702-701, Korea

E-mail: sang@knu.ac.kr

Dr Kang-Jin Cho, Department of Molecular Physiology and Biochemistry, NIAB, Suwon 441-707, Korea

E-mail:kjcho@rda.go.kr

Abbreviations: GjT, Geum japonicum Thunberg; HUVECs, human umbilical vein endothelial cells; MAPKs, mitogen-activated protein kinases; $\mathrm{CD}$, cluster of differentiation; TIMP, tissue inhibitor of metalloproteinase; RT-PCR, reverse transcription-polymerase chain reaction; MMP, matrix metalloproteinase

Key words: Geum japonicum Thunberg, angiogenesis, cell migration, mitogen-activated protein kinase

\section{Introduction}

Cancer is a dynamic process that exhibits the complicated diagnostic symptoms of various types of tissues (1). Cancer progression/metastasis, a hallmark of the disease, is a perplexing sequence of steps, whereby cells intrude neighboring tissue. It is well-known that cells penetrate into blood vessels, circulate and colonize at distant sites, thus becoming metastatic lesions (2).

Angiogenesis is the formation of new blood vessels from a pre-existing vasculature which occurs under physiological conditions (3). The process develops in a multi-step process that is comprised of the peri-vascular detachment of existing vessels, matrix degradation, the migration of endothelial cells and the formation of a functional vascular plexus (4). In a solid tumor, angiogenesis is well-characterized as a critical step for growth, invasion and metastasis. Tumor growth is caused by an imbalance of angiogenic factors in the tumor microenvironment (5). It has been reported that tumor cells promote vessel formation by angiogenic molecules, such as vascular epithelial (VEGF), basic fibroblast (bFGF) and hepatocyte growth factor (HGF), matrix metalloproteinase (MMP) and other tumor-induced molecules (6). As a result, tumor cells were developed by matrix remodeling, migration, stabilization and macrocapillary formation (3). New antiangiogenic compounds have led to a new target in the treatment of cancer.

In clinical trials, various molecular markers such as matrix metalloproteinases (MMPs), CD44, intracellular cell adhesion molecules (ICAM), vascular cell adhesion molecules (VCAM) or urine plasminogen activator receptors (UPAR), play a key role in alleviating tumor cell proliferation during the progression of tumor cells (7). For this reason, a further understanding of the molecular mechanisms of chemotherapeutic agent(s), compound(s), fraction(s) and extract(s) is needed.

Traditional medicines have been effective in treating various degenerative diseases and they have been widely used in the world, especially in Asian countries. We have already documented that several medicinal plants (Wisteria floribunda, Gastrodia elata Blume and Salvia miltiorrhiza Bunge), have been shown to decrease the spread of cancer and metastasis (8-10). In the course of screening for anti- 
tumor agents, we determined that $\mathrm{G} j \mathrm{~T}$ has a potent anti-tumor potential of alleviating tumor cell growth. The whole plant of Geum japonicum Thunberg $(\mathrm{Gj} \mathrm{T})$ has long been used as a diuretic and as an astringent in folk medicine in Korea, China and Japan. $\mathrm{Xu}$ et al reported that triterpene acids from $\mathrm{Gj} \mathrm{T}$ exhibited activity against HIV $(11,12)$. It has also been reported that eugeniin, tannins and several other fractions are closely involved in regulating anti-herpes symptoms, hypertension and muscle ischemia (13-15).

In this study, our present results show that $\mathrm{G} j \mathrm{~T}$ has the potential to inhibit metastatic and angiogenic activity. We demonstrated that an active component of GjT exhibits antiangiogenesis and anti-migration activity, thus suggesting that the fraction will shed light on the development of GjT-derived traditional medicine. Therefore, our goal is to focus on the elucidation of molecular mechanisms regarding the anti-tumor effects of $\mathrm{G} J \mathrm{~T}$, by examining the inhibition of cell proliferation during the attachment, spread, migration and angiogenesis processes in B16 and HUVEC cells.

\section{Materials and methods}

Fractions of Geum japonicum Thunberg. Geum japonicum Thunberg ( GjT) was collected from the Laboratory of Molecular Physiology and Biochemistry, National Institute of Agricultural Biotechnology (NIAB) and dried in an oven at $50^{\circ} \mathrm{C}$. After grinding, the powder was extracted three times with $80 \%$ methanol and the extracts were filtered with filter paper (Whatman No. 2). The extracts were concentrated in a rotary vacuum evaporator at $45^{\circ} \mathrm{C}$ before $80 \%$ of the methanolic fraction was freeze-dried. A fraction of the methanol was fractionated three times with an equal volume of hexane and water (1:1) and then the hexane fraction was concentrated under pressure. The fractions of methylene chloride and $\mathrm{H}_{2} \mathrm{O}(1: 1)$, ethyl acetate and $\mathrm{H}_{2} \mathrm{O}$ (1:1) were conducted in the same way. The yield of each extract is shown in Table I.

Attachment and spreading assays. Attachment and spreading assays were carried out as previously described (9). Briefly, the B16 cells spread to the bottom of each well of the 6-well plates (Greiner, Frickenhausen, Germany) at a concentration of the $\mathrm{Gj}$ T extract $\left(1 \times 10^{4}\right.$ cells/well) for $2 \mathrm{~h}$ (attach assay) or $24 \mathrm{~h}$ (spreading assay) in a $5 \% \mathrm{CO}_{2}$ incubator at $37^{\circ} \mathrm{C}$. The plates were stained by a hematoxylin and eosin (H\&E) stain and photographed, and the attachment ratio was measured and compared to the control.

In vitro wound healing assay. The mouse melanoma cell line B16F1 (B16, Catalog no. CRL-6323) was obtained from the American Type Culture Collection (ATCC, Manassas, VA, USA). B16 cells were cultured in RPMI-1640 supplemented with a $10 \% \mathrm{FBS}$ in a $5 \% \mathrm{CO}_{2}$ incubator at $37^{\circ} \mathrm{C}$. The $\mathrm{B} 16$ cells were attached to the bottom of each well of the 6-well plates (Greiner) and the B16 cells were plated at $1 \times 10^{7}$ cells/well and allowed to attach for $3-5 \mathrm{~h}$ at $37^{\circ} \mathrm{C}$ in a $5 \% \mathrm{CO}_{2}$ atmosphere. The wound lines were made with a blade, drawn on the plate and the medium was changed. The plates were then photographed and incubated as above with a medium containing various concentration levels of the $\mathrm{Gj} \mathrm{T}$ extract. The plates were
Table I. Yield of methylene chloride fraction.

\begin{tabular}{lr}
\hline Fraction & Weight, g (Yield, \%) \\
\hline Geum japonicum Thunberg power & $1500.0(100.0)$ \\
Methanol fraction & $385.0(25.7)$ \\
n-Hexane fraction & $2.7(0.7)$ \\
Methylene chloride fraction & $2.3(0.6)$ \\
Ethyl acetate fraction & $18.0(4.7)$ \\
Aqueous fraction & $178.0(48.6)$ \\
\hline
\end{tabular}

photographed at $20 \mathrm{~h}$ and the wound width was calculated by a microruler (http://www.eeob.iastate.edu/faculty/DrewsC/ htdocs/microruler-links.htm) (16).

In vitro tube formation assay. An in vitro tube formation assay was carried out as previously described (17). Human umbilical vein endothelial cells (HUVECs), which were obtained from the ATCC (passage 2-10), were maintained in EGM-2 medium for HUVECs (Cambrex, no. CC-4176, Walkersville, MD, USA) containing $2.5 \%$ of a fetal bovine serum (FBS, Cambrex, Walkersville, MD, USA), hEGF, hydrocortisone, GA-100 (gentamycin, amphotericin-B), VEGF, hFGF-B (w/heparin), $\mathrm{R}^{3}$-IGF-1, ascorbic acid and heparin.

For an in vitro tube formation assay, 24-well plates were coated with matrigel (BD Bioscience, no. 354234, Franklin Lakes, NJ, USA) at a concentration of $100 \mu \mathrm{l} /$ well, of a medium according to the manufacturer's instructions. After incubation for 2-3 h, the HUVECs were plated on coated dishes at a concentration of $2 \times 10^{4}$ cells/well and incubated at $37^{\circ} \mathrm{C}$ in a $5 \% \mathrm{CO}_{2}$ incubator for $24-48 \mathrm{~h}$. Tube formation was counted by an inverted microscope (Nikon, Tokyo, Japan). The cell images were taken by a Nikon camera (Model No. TS100, Tokyo, Japan).

RT-PCR analysis of the gene expression. Total RNA was extracted by Tri reagent (MRC, catalog no. TR 118), according to the manufacturer's manual. Total RNA (1-10 $\mu \mathrm{g})$ from the tumor cells was converted to first-strand cDNA that was primed with random primer (or Oligo dT) in a reaction volume of $20 \mu \mathrm{l}$, using an RNA PCR kit (iNtRON Biotechnology, Sungnam, Korea), and $4 \mu \mathrm{l}$ of the PCR product were used as a template. The oligo nucleotides were used in PCR amplification with specific primers for mice CD44 (forward, 5'-TCG ATT TGA ATG TAA CCT GCC-3'; reverse, 5'-TGG TGT GTT CTA TAC TCG CCC-3'), TIMP-2 (forward, 5'-GCA TCA CCC AGA AGA AGA GC -3'; reverse, 5'-GGG TCC TCG ATG TCA AGA AA-3') and GAPDH (forward, 5'- ATG TTC CAG TAT GAC TCC AC -3'; reverse, 5'- GCC AAA GTT GTC ATG GAT GA-3') as an internal control. The PCR was carried out for the products of CD44, TIMP-2 and glyceraldehydes-3-phosphate dehydrogenase (GAPDH), with denaturing at $94^{\circ} \mathrm{C}$ for $30 \mathrm{sec}$, annealing at $58^{\circ} \mathrm{C}$ for $30 \mathrm{sec}$ and extension at $72^{\circ} \mathrm{C}$ for $30 \mathrm{sec}$ (9). The linear quantitation of the RT-PCR products was determined by a Gel-doc System (Bio-Rad, Universal-II, San Jose, CA, USA). 
Geum japonicum Thunberg

Extracted with $80 \%$ methanol
Methanol extract
Water layer
Water layer
Water fraction

Figure 1. Fractionation procedure of the methylene chloride fraction of Geum japonicum Thunberg.

Western blot analysis. B16 cells were solubilized in a buffer containing $10 \mathrm{mM}$ of Tris- $\mathrm{HCl}, 1 \%$ of Triton X-100, $50 \mathrm{mM}$ of sodium chloride, $30 \mathrm{mM}$ of sodium pyrophosphate, $50 \mathrm{mM}$ of sodium floride, $100 \mu \mathrm{M}$ of sodium vanadate, $5 \mathrm{mM}$ of EDTA and $1 \mathrm{mM}$ of phenylmethylsufonyl fluoride, adjusted to a $\mathrm{pH}$ of 7.6. The lysates were spun down by centrifugation at $15,000 \mathrm{x} \mathrm{g}$ for $20 \mathrm{~min}$ and supernatants were added to a $2 \mathrm{X}$ SDS loading buffer (125 mM of Tris- $\mathrm{HCl}, 2 \%$ glycerol, $4 \%$ SDS (w/v), $0.05 \%$ mecraptoethanol and $0.05 \%$ bromophenol blue, adjusted to a $\mathrm{pH}$ of 6.8). Electrophoresis was carried out using a one-dimensional SDS-polyacrylamide gel (12\%) and proteins were transferred to nitrocellullose (NC) membranes. The membranes were then blocked for $2 \mathrm{~h}$ in a PBST $(0.05 \%$ of Tween-20) containing 5\% of non-fat skim milk (Seoul Milk, Seoul, Korea) and then incubated overnight in a PBST containing primary antibodies (ERK, Biosource no. 44-654; p-ERK Try185/Tyr187, Biosource no. 44-680; JNK, Cell Signaling no. 9252; p-JNK Try183/Tyr185, Cell Signaling no. 9251; p-38, Cell Signaling no. 9212; p-p38 Try180/Tyr182, Cell Signaling no. 9211), which were diluted to 1:500-2000 in $5 \%$ of a bovine serum albumin. Secondary antibodies were used in horseradish peroxidase conjugated mouse or rabbit $\mathrm{IgG}$. The blots were developed by an ECL system (Pierce, no. 34094, Rockford, IL, USA) in order to identify the detection of each protein band $(9,18)$.

Statistical analyses. Data were expressed as means \pm standard deviation and analyzed using a paired student's t-test program to compare the two groups (Newman-Keuls post test program). A P-value of $<0.05$ was considered statistically significant.

\section{Results and discussion}

To investigate the inhibitory mechanism of the metastatic and angiogenic activity of the Geum japonicum Thunberg $(\mathrm{G} j \mathrm{~T})$ extract, we carried out the partial fractionation of $\mathrm{G} j \mathrm{~T}$. The whole plant $(1.500 \mathrm{~g})$ was added with $80 \%$ methanol and extracted by a rotary mixer. The residue was discarded by centrifugation and the methanolic fraction (385 g) was reextracted with $n$-hexane. The water layer was partitioned with methylene chloride and a methylene chrolode fraction was obtained (2.3 g, $0.6 \%$ yield). The flowchart of the procedure
A

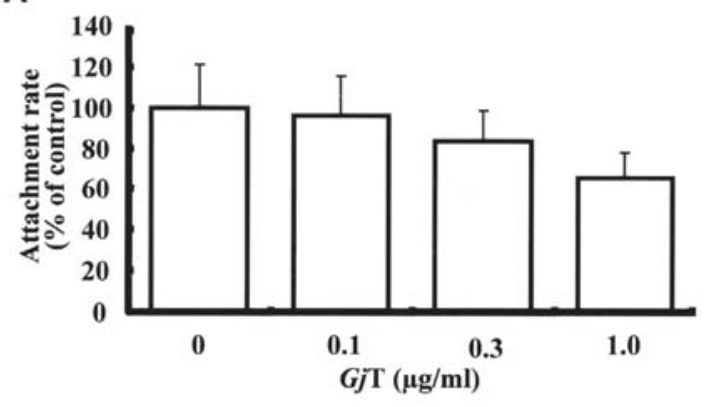

B

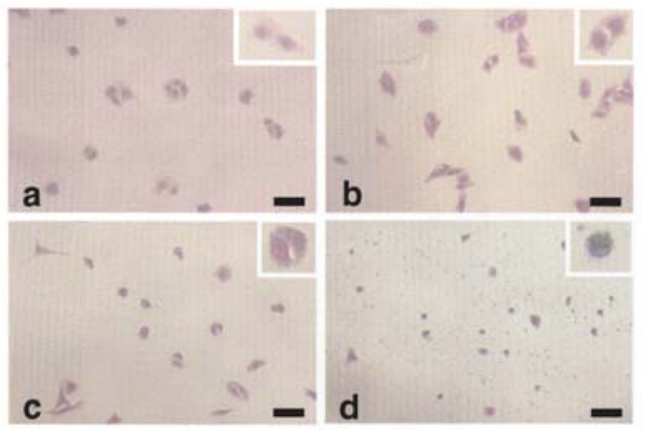

Figure 2. Changes in the cell morphology and spread of the fraction of methylene chloride of Geum japonicum Thunberg in B16 cells using an attachment assay. (A) The inhibition ratio of cell attachment was determined by the $\mathrm{G} j \mathrm{~T}$ extract after $2 \mathrm{~h}$ in a dose-dependent manner. (B) A comparison of cell morphology. B16 cell suspensions were treated with or without different concentrations (a, $0 ; \mathrm{b}, 0.1 ; \mathrm{c}, 0.3$ and $\mathrm{d}, 1 \mu \mathrm{g} / \mathrm{ml}$ ) of the $\mathrm{G} j \mathrm{~T}$ extract after incubation for $24 \mathrm{~h}$ by an inverted microscope; scale bar, $100 \mu \mathrm{m}$.

is shown in Fig. 1. We used this methylene chrolode fraction throughout the experiments.

First, we examined whether the GjT extract affected cell adhesion and spread by using an in vitro cell migration assay in B16 melanoma cells. The inhibition of tumor cell adhesion to the extracellular matrices and basement membrane proved to be an important step in tumor metastasis. As shown in Fig. 2A, $\mathrm{Gj} \mathrm{T}$ treatment $(1.0 \mathrm{mg} / \mathrm{ml})$ inhibited the attachment rate up to $30 \%$ compared to that of the control. This phenomenon can be seen by a contrast microscope (Fig. 2B). In the control, the morphology of the cells did not sustain any damage. By adding the extract at a concentration of $1.0 \mathrm{mg} / \mathrm{ml}$, the growth of cells was significantly inhibited (Fig. 2d), while at milder concentrations, the cells showed slight damage (Fig. 2b and c). These results collectively suggest that the GjT extract, after $2 \mathrm{~h}$ of treatment, exhibited an inhibitory effect on tumor cell adhesion on the culture plate, in a concentration-dependent manner (Fig. 2A and B).

We confirmed also whether $\mathrm{Gj}$ T inhibited the ability of the B16 cells to spread by a wound healing assay. As shown in Fig. 3A, a wound was made (Fig. 3A a) and then cultured onto the plates for $24 \mathrm{~h}$ in order to examine whether it was inhibited. GjT significantly inhibited cell spreading in a dosedependent manner (Fig. 3A c, d and e). The relative inhibition percentage was plotted in Fig. 3B. By adding 1.0 $\mathrm{mg} / \mathrm{ml}$ of $\mathrm{GjT}$, the healing activity was significantly reduced by $82 \%$ (Fig. 3B). These results indicated that the $\mathrm{Gj} \mathrm{T}$ extract inhibited cell attachment and its spread in a concentration-dependent manner in vitro (Fig. 3). There are 
A

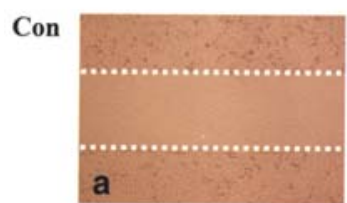

$\mathbf{0}$

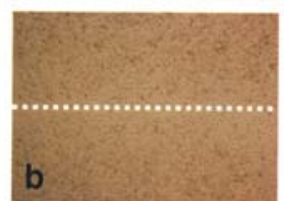

0.3

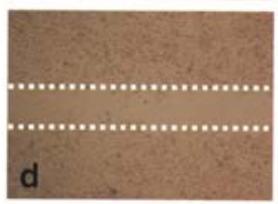

B

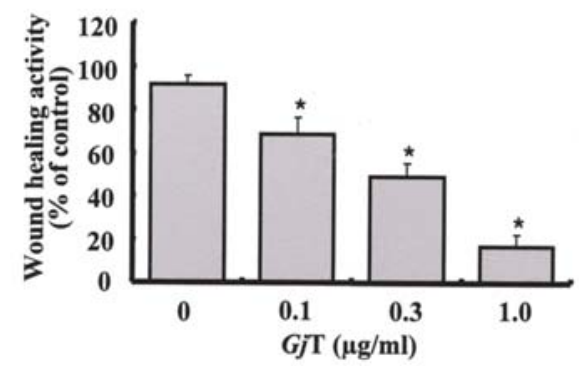

0.1
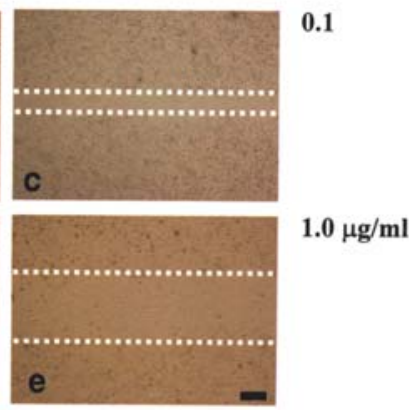

$1.0 \mu \mathrm{g} / \mathrm{ml}$

A

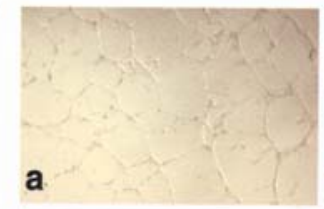

b
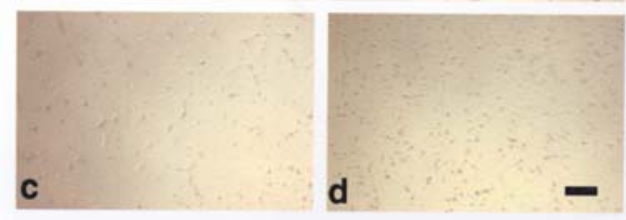

B

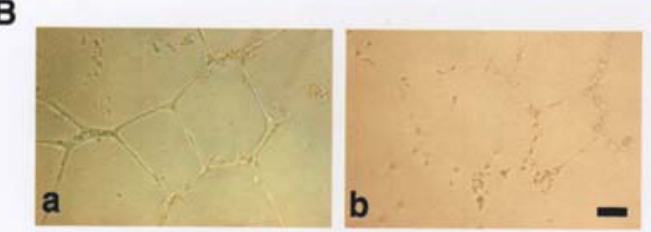

Figure 4. The diffentiation of endothelial cells (HUVECs) into a capillarylike structure. (A) The effect of the GjT extract on the matrigel differentiation of HUVECs. No treatment cells made tube-like structures, but the treated HUVEC cells of the GjT-treated extract did not, and cellular extension was decreased after $24 \mathrm{~h}$. (B) Tubes are already formed within $48 \mathrm{~h}$ of the tube collapsing; scale bar, $100 \mu \mathrm{m}$.

Figure 3. The Geum japonicum Thunberg extract inhibits cell migration in vitro. (A) Monolayers were scratched with a blade to make a wound and the cells were incubated with different concentrations of the $\mathrm{Gj} \mathrm{T}$ extract. The plate was photographed after $20 \mathrm{~h}$. The $\mathrm{G} j \mathrm{~T}$ extract inhibited wound healing activity in a dose-dependent manner in B 16 cells. (B) The quantification of the wound healing assay. Cell migration was quantified by counting the wound width $20 \mathrm{~h}$ after the plate was treated with or without the $\mathrm{Gj}$ T extract. Values are means $\pm \mathrm{SD}$ of independent experiments conducted in triplicate; ${ }^{*} \mathrm{p}<0.05$ is considered statistically significant; scale bar, $100 \mu \mathrm{m}$.

many anti-cancer therapies for which several medicinal plant extracts suppress cell migration and/or motility $(19,20)$. The migration activity of the B16 cells decreased wound healing activity in a dose-dependent manner by the GjT extract. The most remarkable results showed that the $\mathrm{Gj} \mathrm{T}$ extract inhibited cell spreading and migration in vitro.

For this reason, we examined whether the HUVEC differentiation into capillary-like structures (i.e., tube formation) was affected by $\mathrm{Gj}$ T. Since the angiogenic process is characterized by endothelial cell differentiation, in vitro angiogenesis assays were carried out to assess their capability with HUVECs for 24-48 h, with the GjT extract on matrigel. Dose-dependency at four different concentrations $(0.1,0.3$, 1.0 or $3.0 \mu \mathrm{g} / \mathrm{ml}$ ) was also investigated. When non-treated cells were used as a control, the differentiation of HUVECs into capillary-like structures was observed. However, when the HUVEC cells were treated with the GjT extract, the number of capillary-like structures drastically decreased in a dose-dependent manner (Fig. 4A a-d). After $48 \mathrm{~h}$ of incubation, the control morphology was vivid in shape (Fig. 4B a), whereas the tube formation that was treated with $\mathrm{G} j \mathrm{~T}(0.1 \mu \mathrm{g} / \mathrm{ml})$ was significantly decreased (a comparison of the shapes of A-b

A $\begin{array}{lllll}0 & 0.1 & 0.3 & 1.0 & \mu \mathrm{g} / \mathrm{ml}\end{array}$
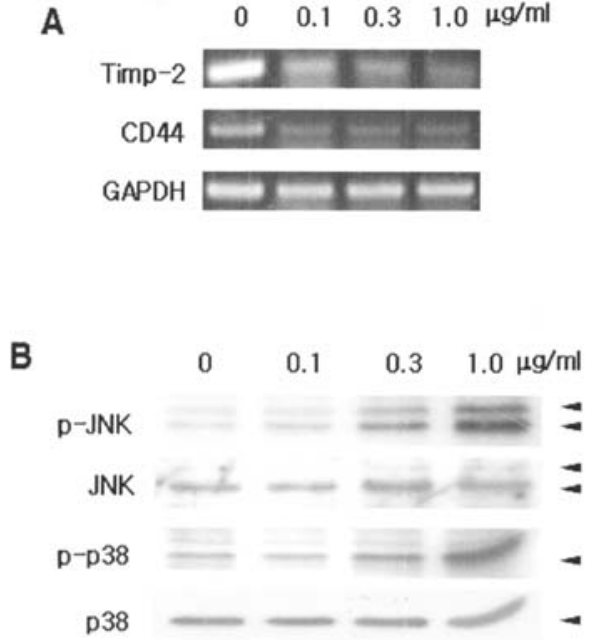

Figure 5. The expression of mRNA levels of MAPK kinases by the Geum japonicum Thunberg extract. (A) The GjT extract suppresses the total amount of CD44 and TIMP-2 RNA levels. (B) A Western blot analysis of the extract from B16 cells was conducted at concentrations of $0,0.1,0.3$ and $1 \mathrm{~g} / \mathrm{ml}$, using antibodies which can detect the phosphorylated forms of ERK, JNK and $\mathrm{p} 38$. The GjT extract increased the phosphorylated forms of JNK in a dose-dependent manner.

and B-b). Together, these results suggest that tube formation was affected by the GjT extract in concentration- and timedependent manner.

CD44 is an extra-cellular membrane protein that is involved in cell migration, tumorigenesis, metastasis and immune responses via its involvement with MMP-2 and -9 (21). MMP-2 is co-localized with MT-MMP-1 and TIMP-2, which are activators and activation-enhancing factors, respectively, for proMMP-2. Therefore, TIMP-2 was involved 
in the formation of fibrovascular tissues (22). However, TIMP-2 abrogated angiogenic factor-induced endothelial cell proliferation in vitro and angiogenesis in vivo independently of MMP inhibition (23). When B16 melanoma cells were treated with $0.1,0.3$ and $1 \mu \mathrm{g} / \mathrm{ml}$ of the GjT extract, the CD44 and TIMP-2 mRNA expressions were dramatically reduced in a concentration-dependent manner (Fig. 5A). These results strongly suggest that the GjT extract affects CD44 and TIMP-2 levels, showing that it may be involved in cell migration via altered signaling by the CD44 and TIMP-2 associated proteins.

The signal transduction pathways of the mitogenactivated protein kinases (MAPKs) are among the most widespread mechanisms of cellular regulation (24). All eukaryotic cells possess multiple MAPK pathways, each of which is preferentially recruited by a distinct set of stimuli, thereby allowing multiple divergent inputs, in parallel, to the cell response (25). Mammalian MAPK pathways can be recruited by a wide variety of different stimuli ranging from hormones, such as insulin and growth hormones, epidermal, platelet-derived and fibroblast growth factors, angiotensin-II, endothelin, inflammatory cytokines of the tumor necrosis factor (TNF) family and environmental stress (osmotic shock, ionizing radiation and ischemia injury, etc.). ERK 1 and 2 phosphorate and activate the two transcription factors and other protein kinases, thereby influencing a large variety of cellular processes (26).

In order to prove the molecular mechanism of the metastatic and angiogenic potential in cancer cells, we carried out an analysis of the MAPK expression by treatment with the GjT extract. Cell lysates were probed for total and phospho-forms of ERK, JNK or p38 and the cells were detected by the distinct expression of the phosphorylated form of proteins. Expressions were detected by the form of phospho-JNK in a dose-dependent manner (Fig. 5B). The JNK kinase activity that was shown in cell-treated GjT for $1 \mathrm{~h}$, was $>3.3$-fold that of the control. The expression of phosphoERK did not change at a concentration of $1.0 \mu \mathrm{g} / \mathrm{ml}$ (data not shown) (27), whereas that of p-JNK and p-p38 greatly increased more than that of the control. Collectively, these results suggest that the signaling induced by $\mathrm{Gj}$ T is closely associated with the dual amplification of JNK and p38 phosphorylation. In order to find a novel tumor-suppressor agent, most of these functions require the modulation of different targets in angiogenesis, such as the growth factor VEGF, matrix metalloproteinase MMP-2 and -9, and integrin $\alpha_{v} \beta_{3}$. Herein, we demonstrated that the GjT extract inhibited the spreading and/or migration of B16 cells and blocked HUVEC differentiation on matrigel and actin as inhibitors of in vitro angiogenesis.

In this study, we proved that the inhibition of cell migration and motility by GjT was increased with phospho-JNK and p38 expression in a dose-dependent manner (Fig. 5B). However, we anticipate the results of testing done using active compound(s) in $\mathrm{Gj} \mathrm{T}$.

\section{Acknowledgements}

This work was supported by the Technology Development Program for Agriculture and Forestry, Ministry of Agriculture and Forestry, Republic of Korea (K.-J.C.) and partial support was received from MAF/ARPC through the Grape Research Projects Group on anticancer in vitro assays (S .-H.L.).

\section{References}

1. Yamaguchi $\mathrm{H}$, Wyckoff $\mathrm{J}$ and Condeelis $\mathrm{J}$ : Cell migration in tumors. Curr Opin Cell Biol 17: 559-564, 2005.

2. Stamenkovic I: Extracellular matrix remodelling: the role of matrix metalloproteinases. J Pathol 200: 448-464, 2003.

3. Jakob C, Sterz J, Zavrski I, Heider U, Kleeberg L, Fleissner C, Kaiser M and Sezer O: Angiogenesis in multiple myeloma. Eur J Cancer 42: 1581-1590, 2006.

4. Chaplain MA, McDougall SR and Anderson AR: Mathematical modeling of tumor-induced angiogenesis. Annu Rev Biomed Eng 8: 233-257, 2006.

5. Deryugina EI and Quigley JP: Matrix metalloproteinases and tumor metastasis. Cancer Metastasis Rev 25: 9-34, 2006.

6. Ribatti D, Vacca A, De Falco G, Roccaro A, Roncali L and Dammacco F: Angiogenesis, angiogenic factor expression and hematological malignancies. Anticancer Res 21: 4333-4339, 2001.

7. Kobayashi H, Suzuki M, Kanayama N, Nishida T, Takigawa M and Terao T: CD44 stimulation by fragmented hyaluronic acid induces upregulation of urokinase-type plasminogen activator and its receptor and subsequently facilitates invasion of human chondrosarcoma cells. Int J Cancer 102: 379-389, 2002.

8. Heo JC, Park JY, Lee JM, Kwon TK, Kim SU, Chung SK and Lee SH: Wisteria floribunda gall extract inhibits cell migration in mouse B16F1 melanoma cells by regulating CD44 expression and GTP-RhoA activity. J Ethnopharmacol 102: 10-14, 2005.

9. Heo JC, Woo SW, Son M, Kweon MA, Park JY, Choi WS, Chang KT, Kim SU, Yoon EK, Kim YH and Lee SH: Antitumor activity of Gastrodia elata Blume is closely associated with a GTP-Ras-dependent pathway. Oncol Rep 18: 849-853, 2007.

10. Lee DS and Lee SH: Biological activity of dihydrotanshinone I: effect on apoptosis. J Biosci Bioeng 89: 292-293, 2000.

11. Xu HX, Zeng FQ, Wan M, Sim KY: Anti-HIV triterpene acids from Geum japonicum. J Nat Prod 59: 635-643, 1996.

12. Xu HX, Ming DS, Dong H and But PP: A new anti-HIV triterpene from Geum japonicum. Chem Pharm Bull 48: 1367-1369, 2000.

13. Cheung WL, Cheng L, Liu H, Gu X and Li M: The dual actions of angiogenesis and anti-apoptosis induced by an isolated fraction from Geum japonicum repair muscle ischemia. Arch Biochem Biophys 459: 91-97, 2007.

14. Xie YW, Xu HX, Dong H, Fiscus RR and But PP: Role of nitric oxide in the vasorelaxant and hypotensive effects of extracts and purified tannins from Geum japonicum. J Ethnopharmacol 109: 128-133, 2007.

15. Kurokawa M, Hozumi T, Basnet P, Nakano M, Kadota S, Namba T, Kawana T and Shiraki K: Purification and characterization of eugeniin as an anti-herpesvirus compound from Geum japonicum and Syzygium aromaticum. J Pharmacol Exp Ther 284: 728-735, 1998 .

16. Moon SH, Heo JC, Fine RL, Kim HM, Kim SU, Yoon BD and Lee SH: BRD-glucan exhibits potent immunochemotherapeutic activity in vitro and in vivo. Int J Mol Med 26: 395-404, 2005.

17. Heo JC, Park JY, Woo SU, Lee MS, Rho JR, Lee HJ, Kim SU, Kho YH and Lee SH: Dykellic acid inhibits cell migration and tube formation by RhoA-GTP expression. Biol Pharm Bull 29: 2256-2259, 2006

18. Lee SH, Youk ES, Lee HJ, Kho YH, Kim HM and Kim SU: Dykellic acid inhibits camptothecin-induced caspase-3 protease activation. Biochem Biophys Res Commun 302: 539-544, 2003.

19. Harris SR and Thorgeirsson UP: Tumor angiogenesis: biology and therapeutic prospects. In Vivo 12: 563-570, 1998.

20. Rao J and Li N: Microfilament actin remodeling as a potential target for cancer drug development. Curr Cancer Drug Targets 4: 345-354, 2004.

21. Weber GF, Ashkar S, Glimcher MJ and Cantor H: Receptorligand interaction between CD44 and osteopontin (Eta-1). Science 271: 509-512, 1996.

22. Noda K, Ishida S, Inoue M, Obata K, Oguchi Y, Okada Y and Ikeda E: Production and activation of matrix metalloproteinase-2 in proliferative diabetic retinopathy. Invest Ophthalmol Vis Sci 44: 2163-2170, 2003.

23. Seo DW, Li H, Guedez L, Wingfield PT, Diaz T, Salloum R, Wei B and Stetler-Stevenson WG: TIMP-2 mediated inhibition of angiogenesis: an MMP-independent mechanism. Cell 114: 171-180, 2003. 